\title{
A NEW ASTROBIOLOGICAL MODEL OF THE ATMOSPHERE OF TITAN
}

\author{
K. Willacy ${ }^{1}$, M. Allen ${ }^{2,3}$, and Y. YunG ${ }^{3}$ \\ ${ }^{1}$ MS 169-507, Caltech/Jet Propulsion Laboratory, 4800 Oak Grove Drive, Pasadena, CA 91109, USA; Karen.Willacy@jpl.nasa.gov \\ ${ }^{2}$ Caltech/Jet Propulsion Laboratory, 4800 Oak Grove Drive, Pasadena, CA 91109, USA \\ ${ }^{3}$ Division of Geological and Planetary Science, California Institute of Technology, Pasadena, CA 91125, USA \\ Received 2016 May 3; revised 2016 July 11; accepted 2016 July 15; published 2016 September 23
}

\begin{abstract}
We present results of an investigation into the formation of nitrogen-bearing molecules in the atmosphere of Titan. We extend a previous model to cover the region below the tropopause, so the new model treats the atmosphere from Titan's surface to an altitude of $1500 \mathrm{~km}$. We consider the effects of condensation and sublimation using a continuous, numerically stable method. This is coupled with parameterized treatments of the sedimentation of the aerosols and their condensates, and the formation of haze particles. These processes affect the abundances of heavier species such as the nitrogen-bearing molecules, but have less effect on the abundances of lighter molecules. Removal of molecules to form aerosols also plays a role in determining the mixing ratios, particularly of $\mathrm{HNC}$, $\mathrm{HC}_{3} \mathrm{~N}$, and $\mathrm{HCN}$. We find good agreement with the recently detected mixing ratios of $\mathrm{C}_{2} \mathrm{H}_{5} \mathrm{CN}$, with condensation playing an important role in determining the abundance of this molecule below $500 \mathrm{~km}$. Of particular interest is the chemistry of acrylonitrile $\left(\mathrm{C}_{2} \mathrm{H}_{3} \mathrm{CN}\right)$ which has been suggested by Stevenson et al. as a molecule that could form biological membranes in an oxygen-deficient environment. With the inclusion of haze formation, we find good agreement of our model predictions of acrylonitrile with the available observations.
\end{abstract}

Key words: planets and satellites: atmospheres - planets and satellites: composition - planets and satellites: individual (Titan)

\section{INTRODUCTION}

A major goal of planetary exploration is to obtain a fundamental understanding of planetary environments, both as they are currently and as they were in the past. This knowledge can be used to explore the questions of (a) how conditions for planetary habitability arose and (b) the origins of life. Titan is a unique object of study in this quest. Other than Earth itself, and Pluto (which has also been observed to have photochemically produced haze; Stern et al. 2015; Gladstone et al. 2016), Titan is the only solar system body demonstrated to have complex organic chemistry occurring today. Its atmospheric properties-(1) a thick $\mathrm{N}_{2}$ atmosphere, (2) a reducing atmospheric composition, (3) energy sources for driving disequilibrium chemistry, and (4) an aerosol layer for shielding the surface from solar UV radiation-suggest that it is a counterpart of the early Earth, before the latter's reducing atmosphere was eradicated by the emergence and evolution of life (Coustenis \& Taylor 1999; Lunine 2005; Lorenz \& Mitton 2008).

A significant number of photochemical models have been developed to investigate the distribution of hydrocarbons in Titan's atmosphere (Strobel 1974; Yung et al. 1984; Lara et al. 1996; Wilson \& Atreya 2004; De La Haye et al. 2008; Lavvas et al. 2008a, 2008b; Krasnopolsky 2009). Recently, more constraints have been placed on the abundance of hydrocarbons and nitriles in the mesosphere of Titan $(500-1000 \mathrm{~km})$ from Cassini/UVIS stellar occultations (Koskinen et al. 2011; Kammer et al. 2013). In combination with the updated version of Cassini/ CIRS limb view (Vinatier et al. 2010), the complete profiles of $\mathrm{C}_{2} \mathrm{H}_{2}, \mathrm{C}_{2} \mathrm{H}_{4}, \mathrm{C}_{6} \mathrm{H}_{6}, \mathrm{HCN}$, and $\mathrm{HC}_{3} \mathrm{~N}$ are revealed for the first time. $\mathrm{C}_{3}$ compounds, including $\mathrm{C}_{3} \mathrm{H}_{6}$, were modeled by $\mathrm{Li}$ et al. (2015), and the agreement with observations (Nixon et al. 2013) is satisfactory. The chemistry of many of these nitrogen molecules has recently been modeled by Loison et al. (2015).
In this paper, we introduce our updated Titan chemical model that includes the formation of such potentially astrobiologically important molecules as acrylonitrile. In addition to the usual gas phase chemistry, it also includes a numerically stable treatment of the condensation and sublimation, allowing the formation and destruction of ices in the lower atmosphere to be tracked. Haze formation is also included in a parameterized fashion, allowing for the permanent removal of molecules from the atmosphere. We present here the effects of condensation on the nitrogen chemistry. The interaction of hydrocarbons and nitrile species in the condensed phase is complex and is beyond the scope of this paper (see, for example, Figures 1 and 2 of Anderson et al. 2016).

We begin with describing our updated model and, in particular, our treatment of condensation and sublimation (Section 2). We use this updated model to consider the chemistry in Titan's atmosphere from the surface of the moon to an altitude of $1500 \mathrm{~km}$. We explore how condensation processes and haze formation affect the predicted gas phase abundances of observable molecules (Section 3). We also consider where the condensates form within the atmosphere (Section 2.2). Section 4 presents our conclusions.

\section{THE MODEL}

We use the Caltech/JPL photochemical model (KINETICS; Allen et al. 1981) with a recently updated chemical network (appendix), and with the addition of condensation and sublimation processes to explore the atmospheric chemistry of Titan. The 1D model solves the mass continuity equation from the surface of Titan to $1500 \mathrm{~km}$ altitude:

$$
\frac{\partial n_{i}}{\partial t}+\frac{\partial \psi_{i}}{\partial z}=P_{i}-L_{i}
$$

where $n_{i}$ is the number density of species $i$, and $P_{i}$ and $L_{i}$ are its chemical production and loss rates respectively. $\psi_{i}$ is the 

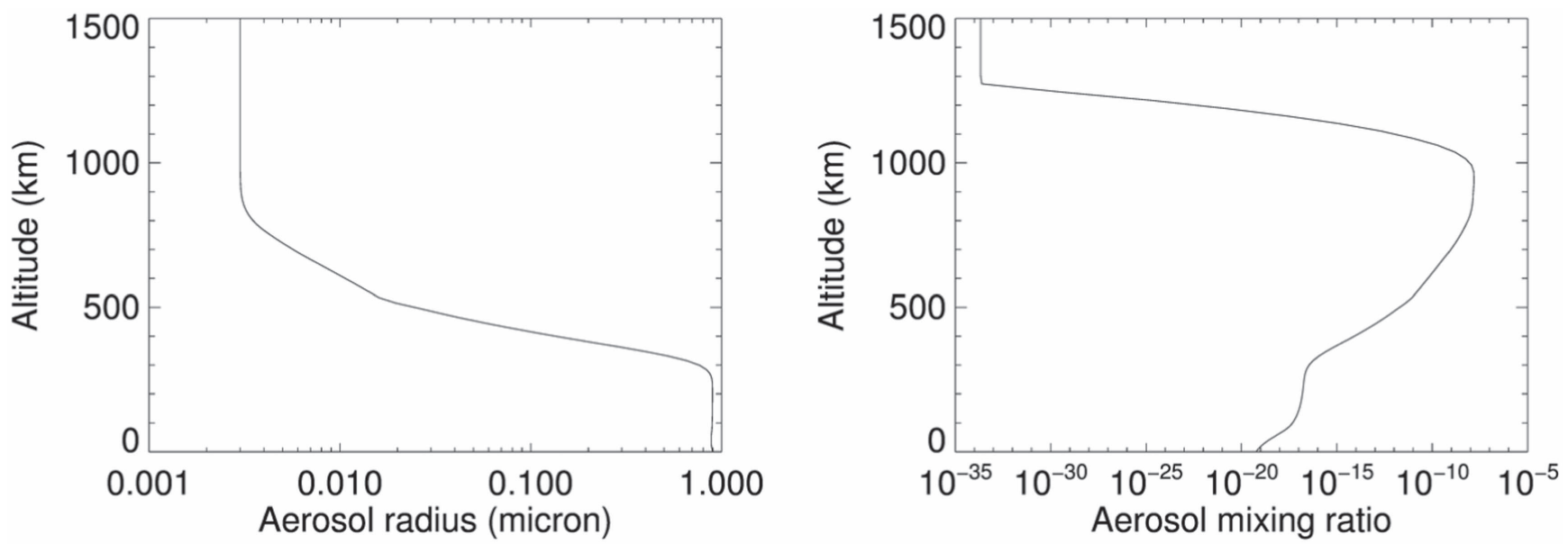

Figure 1. Aerosol properties from Lavvas et al. (2010) derived from a microphysical model validated against DISR observations. Left: the mean radius of particles. Right: the mixing ratio of particles.

Table 1

The Species Included in the Model

\begin{tabular}{|c|c|}
\hline Family & Molecule \\
\hline & $\mathrm{H}, \mathrm{H}_{2}$ \\
\hline Hydrocarbons & $\begin{array}{c}\mathrm{C} \mathrm{CH} \mathrm{CH}{ }_{2}^{3} \mathrm{CH}_{2} \mathrm{CH}_{3} \mathrm{CH}_{4} \mathrm{C} 2 \mathrm{C}_{2} \mathrm{H} \mathrm{C}_{2} \mathrm{H}_{2} \mathrm{C}_{2} \mathrm{H}_{3} \mathrm{C}_{2} \mathrm{H}_{4} \mathrm{C}_{2} \mathrm{H}_{5} \mathrm{C}_{2} \mathrm{H}_{6} \mathrm{C}_{3} \mathrm{C}_{3} \mathrm{H} \mathrm{C}_{3} \mathrm{H}_{2} \mathrm{C}_{3} \mathrm{H}_{3} \mathrm{C}_{2} \mathrm{CCH}_{2} \mathrm{CH}_{3} \mathrm{C}_{2} \mathrm{H} \mathrm{C}_{3} \mathrm{H}_{5} \mathrm{C}_{3} \mathrm{H}_{6} \mathrm{C}_{3} \mathrm{H}_{7} \mathrm{C}_{3} \mathrm{H}_{8} \mathrm{C}_{4} \mathrm{H} \mathrm{C}_{4} \mathrm{C}_{2} \\
\mathrm{C}_{4} \mathrm{H}_{3} \mathrm{C}_{4} \mathrm{H}_{4} \mathrm{C}_{4} \mathrm{H}_{5} \text { 1- } \mathrm{C}_{4} \mathrm{H}_{6} \text { 1,2- } \mathrm{C}_{4} \mathrm{H}_{6} 1,3-\mathrm{C}_{4} \mathrm{H}_{6} \mathrm{C}_{4} \mathrm{H}_{8} \mathrm{C}_{4} \mathrm{H}_{9} \mathrm{C}_{4} \mathrm{H}_{10} \mathrm{C}_{5} \mathrm{H}_{3} \mathrm{C}_{5} \mathrm{H}_{4} \mathrm{C}_{6} \mathrm{H} \mathrm{C}_{6} \mathrm{H}_{2} \mathrm{C}_{6} \mathrm{H}_{3} \mathrm{C}_{6} \mathrm{H}_{4} \mathrm{C}_{6} \mathrm{H}_{5} l-\mathrm{C}_{6} \mathrm{H}_{6} \mathrm{C}_{6} \mathrm{H}_{6} \mathrm{C}_{8} \mathrm{H}_{2}\end{array}$ \\
\hline Nitrogen-molecules & $\begin{array}{l}\mathrm{N} \mathrm{NH} \mathrm{NH} \mathrm{NH}_{3} \mathrm{~N}_{2} \mathrm{H} \mathrm{N}_{2} \mathrm{H}_{2} \mathrm{~N}_{2} \mathrm{H}_{3} \mathrm{~N}_{2} \mathrm{H}_{4} \mathrm{CN} \mathrm{HCN} \mathrm{HNC} \mathrm{H} \mathrm{CN} \mathrm{CHCN} \mathrm{CH} \mathrm{CN} \mathrm{CH}_{3} \mathrm{CN} \mathrm{C}_{2} \mathrm{H}_{3} \mathrm{CN} \mathrm{C}_{2} \mathrm{H}_{5} \mathrm{CN} \mathrm{C}_{3} \mathrm{H}_{5} \mathrm{CN} \mathrm{C}_{2} \mathrm{~N}_{2} \mathrm{HC}_{2} \mathrm{~N}_{2} \mathrm{C}_{3} \mathrm{~N} \\
\mathrm{HC}_{3} \mathrm{~N} \mathrm{HC}_{4} \mathrm{~N} \mathrm{CH}_{3} \mathrm{C}_{2} \mathrm{CN} \mathrm{H}_{2} \mathrm{C}_{3} \mathrm{~N} \mathrm{C}_{4} \mathrm{~N}_{2} \mathrm{HC}_{5} \mathrm{~N} \mathrm{C}_{6} \mathrm{~N}_{2} \mathrm{CH}_{2} \mathrm{NH} \mathrm{CH}_{2} \mathrm{NH}_{2} \mathrm{CH}_{3} \mathrm{NH} \mathrm{CH}_{3} \mathrm{NH}_{2}\end{array}$ \\
\hline Condensed molecules & $\begin{array}{r}\mathrm{C}_{2} \mathrm{H}_{2}^{c} \mathrm{C}_{2} \mathrm{H}_{4}^{c} \mathrm{C}_{2} \mathrm{H}_{6}^{c} \mathrm{CH}_{2} \mathrm{CCH}_{2}^{c} \mathrm{CH}_{3} \mathrm{C}_{2} \mathrm{H}^{c} \mathrm{C}_{3} \mathrm{H}_{6}^{c} \mathrm{C}_{3} \mathrm{H}_{8}^{c} \mathrm{C}_{4} \mathrm{H}_{2}^{c} \mathrm{C}_{4} \mathrm{H}_{4}^{c} 1-\mathrm{C}_{4} \mathrm{H}_{6}^{c} 1,2-\mathrm{C}_{4} \mathrm{H}_{6}^{c} 1,3-\mathrm{C}_{4} \mathrm{H}_{6}^{c} \mathrm{C}_{4} \mathrm{H}_{8}^{c} \mathrm{C}_{4} \mathrm{H}_{10}^{c} \mathrm{C}_{5} \mathrm{H}_{4}^{c} l-\mathrm{C}_{6} \mathrm{H}_{6}^{c} \mathrm{C}_{6} \mathrm{H}_{6}^{c} \mathrm{HCN}^{c} \\
\mathrm{HNC}^{c} \mathrm{CH}_{3} \mathrm{CN}^{c} \mathrm{C}_{2} \mathrm{H}_{3} \mathrm{CN}^{c} \mathrm{C}_{2} \mathrm{H}_{5} \mathrm{CN}^{c} \mathrm{C}_{3} \mathrm{H}_{5} \mathrm{CN}^{c} \mathrm{C}_{2} \mathrm{~N}_{2}^{c} \mathrm{C}_{4} \mathrm{~N}_{2}^{c} \mathrm{C}_{6} \mathrm{~N}_{2}^{c} \mathrm{HC}_{3} \mathrm{~N}^{c} \mathrm{HC}_{5} \mathrm{~N}^{c} \mathrm{CH}_{3} \mathrm{C}_{2} \mathrm{CN}^{c} \mathrm{CH}_{2} \mathrm{NH}^{c} \mathrm{CH}_{3} \mathrm{NH}_{2}^{c} \mathrm{NH}_{3}^{c} \mathrm{~N}_{2} \mathrm{H}_{2}^{c} \mathrm{~N}_{2} \mathrm{H}_{4}^{c}\end{array}$ \\
\hline
\end{tabular}

Note. A superscript of ${ }^{c}$ indicates the molecule is condensed.

vertical flux of $i$ calculated from

$$
\begin{aligned}
\psi_{i}= & -\frac{\partial n_{i}}{\partial z}\left(D_{i}+K_{z z}\right)-n_{i}\left(\frac{D_{i}}{H_{i}}+\frac{K_{z z}}{H_{a}}\right) \\
& -n_{i} \frac{\partial T}{\partial z} \frac{\left(1+\alpha_{i}\right) D_{i}+K_{z z}}{T},
\end{aligned}
$$

where $D_{i}$ and $H_{i}$ are the molecular diffusion coefficient and the scale height for species $i$ respectively, $H_{a}$ is the atmospheric scale height, $\alpha_{i}$ is the thermal diffusion coefficient of species $i$, $T$ is the temperature, and $K_{z z}$ is the eddy diffusion coefficient. The eddy diffusion coefficient used here is taken from Li et al. (2015) and can be summarized as

$$
\begin{aligned}
& \log K_{z z}(z) \\
& =\left\{\begin{array}{l}
\log \left(3 \times 10^{3}\right), z<z_{1} \\
\log \left(3 \times 10^{3}\right) \frac{z_{2}-z}{z_{2}-z_{1}}+\log \left(2 \times 10^{7}\right) \frac{z-z_{1}}{z_{2}-z_{1}} \\
z_{1} \leqslant z<z_{2} \\
\log \left(2 \times 10^{7}\right) \frac{z_{3}-z}{z_{3}-z_{1}}+\log \left(2 \times 10^{6}\right) \frac{z-z_{2}}{z_{3}-z_{2}} \\
z_{2} \leqslant z<z_{3} \\
\log \left(2 \times 10^{6}\right) \frac{z_{4}-z}{z_{4}-z_{3}}+\log \left(4 \times 10^{8}\right) \frac{z-z_{3}}{z_{4}-z_{3}} \\
z_{3} \leqslant z<z_{4} \\
\log \left(4 \times 10^{8}\right), z \geqslant z_{4}
\end{array}\right.
\end{aligned}
$$

The atmospheric density and temperature profiles are also taken from $\mathrm{Li}$ et al. (2015), and are based on the T40 Cassini flyby (Westlake et al. 2011).

Aerosols are included in our model, both for the absorption of UV radiation and to provide surfaces onto which molecules can condense. The aerosol properties are from Lavvas et al. (2010) who derived them from a microphysical model validated against Cassini/Descent Imager Spectral Radiometer observations. Their results provide the mixing ratio and surface area of aerosol particles as a function of altitude (Figure 1). To calculate the absorption of UV by dust, we assume absorbing aerosols with extinction cross-sections that are independent of wavelength (Li et al. 2014, 2015).

\subsection{Boundary Conditions}

The lower boundary of our model is the surface of Titan and the upper boundary is at $1500 \mathrm{~km}$. For $\mathrm{H}$ and $\mathrm{H}_{2}$ the flux at the lower boundary is zero and at the top of the atmosphere these molecules are allowed to escape with velocities of $2.4 \times 10^{4} \mathrm{cms}^{-1}$ and $6.1 \times 10^{3} \mathrm{cms}^{-1}$ respectively (equivalent to fluxes of $3.78 \times 10^{8} \mathrm{H}$ atoms $\mathrm{cm}^{-2}$ and $6.2 \times 10^{9} \mathrm{H}_{2}$ molecules $\mathrm{cm}^{-2}$ ). For all other gaseous species, the concentration gradient at the lower boundary is assumed to be zero, while they have zero flux at the top boundary. Observations suggest that $\mathrm{CH}_{4}$ can escape from the top of the atmosphere by sputtering (de La Haye et al. 2007), but the same effect can be generated in models by applying a larger eddy diffusivity (Yelle et al. 2008; Li et al. 2014, 2015), which is the approach 
we have taken here. Condensed species have zero flux at both the upper and lower boundaries.

Table 1 provides a list of the molecules in our model. The mixing ratio of $\mathrm{N}_{2}$ is set according to the observational data and held fixed, with values below $50 \mathrm{~km}$ taken from the Huygens observations (Niemann et al. 2005) and above $1000 \mathrm{~km}$ from Cassini/UVIS data (Kammer et al. 2013). Between 50 and $1000 \mathrm{~km}$ the mixing ratio is assumed to be 0.98 . The mixing ratio of $\mathrm{CH}_{4}$ is fixed to the observed (super-saturated) values (Niemann et al. 2010) below the tropopause and allowed to vary above this.

\subsection{Condensation and Sublimation}

Condensation occurs when the saturation ratio, $S$, of a molecule is greater than one. $S$ is defined as $n(x) / n_{\text {sat }}(x)$, where $n(x)$ is the gas phase mixing ratio of species $x$ and $n_{\mathrm{sat}}(x)$ is its saturated density derived from the saturated vapor pressure. For $S<1$, condensation is switched off and sublimation of any adsorbed molecules can occur. The abrupt change in behavior at $S=1$ can lead to numerical instabilities where the system oscillates between the condensation and sublimation regimes. In previous Titan models, various methods have been used to smooth out the transition and prevent such instabilities. For example, Yung et al. (1984) parameterized the condensation rate in terms of $S$ :

$$
\text { Loss rate } \propto-\frac{S-1}{S} .
$$

This results in a relatively constant loss rate as a function of $S$. A more complicated expression was used by Lavvas et al. (2008a) to ensure that the loss rate increases with increasing saturation ratios:

$$
\text { Loss rate } \propto-(S-1) \frac{\exp \left(-0.5 / \ln (S+1)^{2}\right)}{\ln (S+1)^{2}} \text { for } S>1 \text {. }
$$

Other expressions that have been invoked include

$$
\text { Loss rate } \propto-\ln S
$$

(Krasnopolsky 2009).

Here we use a numerically stable method to determine the net condensation rate. The rate at which molecules condense onto a pre-existing aerosol particle is given by the collision rate with the particle:

$$
k_{c}=\alpha_{x} \sigma v_{x} n(x) \text { molecules } \mathrm{s}^{-1},
$$

where $\alpha$ is the sticking coefficient of molecule $x$ (where $\left.\alpha_{x} \leqslant 1\right), \sigma$ is the collisional cross-section of the particles, $v_{x}$ is the gas phase velocity of $x$, and $n(x)$ is its number density. For a pure ice, the saturated vapor pressure is measured when the condensation and sublimation processes are in equilibrium. In this scenario

$$
k_{c} n_{\text {sat }}(x)=k_{s} \Theta_{x},
$$

where $k_{s}$ is the sublimation rate and $\Theta_{x}$ is the surface coverage of molecule $x$. In the case of a pure ice, $\Theta_{x}=1$, and hence the sublimation rate, $k_{s}=k_{c} n_{\mathrm{sat}}(x)$. The net condensation rate, $J_{c}$ is therefore

$$
J_{c}=\alpha_{x} \sigma v_{x}\left[n(x)-n_{\mathrm{sat}}(x) \Theta_{x}\right] \text { molecules } \mathrm{s}^{-1} .
$$

When sublimation is taking place from a mixture of ices (rather than from pure ice) $\Theta$ will be less than one and the resulting gas phase abundance will be lower than the saturated value. $\Theta$ is calculated from

$$
\Theta=n\left(x^{c}\right) / \Sigma_{y} n\left(y^{c}\right),
$$

where $n\left(x^{c}\right)$ is the number density of $x$ in the condensed phase, $\Sigma_{y} n\left(y^{c}\right)$ is the total number density of all molecules condensed onto the grain surface. We assume that the ices are well-mixed, so that the composition of the surface from which sublimation occurs reflects that of the bulk of the ice.

To determine the saturated densities used in this paper, we use the expressions for the saturated vapor pressure given in Table 2. The values from these fits are extrapolated as necessary to provide saturation vapor pressures over a wider range of temperatures. Figure 2 compares the predicted mixing ratios of $\mathrm{HCN}$ and $\mathrm{C}_{2} \mathrm{H}_{2}$ with the value predicted directly from the saturated vapor pressure. It can be seen that the model produces good agreement with the saturation vapor pressure in regions where the gas is saturated.

\subsection{Sedimentation and Haze Formation}

We assume that the abundance, size, and location of the aerosol particles is fixed. In reality, the particles do not remain at the same altitude but rather sediment out toward the surface of Titan, taking any condensates with them. To mimic this effect, we have included a loss process for condensed molecules that removes them from the model atmosphere with a rate coefficient of $10^{-10} \mathrm{~s}^{-1}$. All condensed species are assumed to be lost at the same rate. The assumed size of this reaction rate is somewhat arbitrary and, to test the sensitivity of our results to its value, we also considered a loss rate of $10^{-12}$ molecules $\mathrm{s}^{-1}$. Changing the rate was found to have no effect on the predicted gas phase mixing ratios.

In addition to the condensation of ice or liquids onto existing aerosols, molecules can also be incorporated into new or existing aerosols. In this scenario, the molecules are then unavailable for return to the gas via sublimation and are permanently removed from the gas (Liang et al. 2007). This process is simulated using rates that are proportional to the collision rates between aerosols (assuming mean radii provided by Lavvas et al. 2010) and molecules. We simulate this by adding reactions that remove the molecules from the gas with

$$
X+\text { haze }=\text { haze } k=\beta v \sigma n_{g} \mathrm{~s}^{-1},
$$

where $n_{g}$ is the mixing ratio of aerosol particles, and $\beta$ is an efficiency factor ranging from 0.01 to 10 depending on the molecule. The value of $\beta$ was chosen for each molecule to maximize the agreement of the models with the observations. The molecules to be removed in this way are $\operatorname{HCN}(\beta=0.01)$, $\mathrm{C}_{2} \mathrm{H}_{3} \mathrm{CN}(\beta=0.1), \mathrm{HC}_{3} \mathrm{~N}$, and HNC $(\beta=10) \mathrm{C}_{2} \mathrm{H}_{5} \mathrm{CN}$ $(\beta=1)$. Other molecules are assumed not to condense in this way-for these molecules, the agreement of the models with observations is sufficiently good without invoking an additional loss mechanism such as haze formation. 
Table 2

Expressions Used to Calculate the Saturated Vapor Pressures

\begin{tabular}{|c|c|c|c|}
\hline Molecule & $\begin{array}{l}\text { Expression for } \log P_{\text {sat }} \\
\quad(\mathrm{mmHg})\end{array}$ & $\begin{array}{l}\text { Temp Range } \\
\text { (K) }\end{array}$ & Notes \\
\hline $\mathrm{CH}_{4}$ & $6.84570-435.6214 /(\mathrm{T}-1.639)$ & $91-189$ & Yaws (2007) \\
\hline \multirow[t]{2}{*}{$\mathrm{C}_{2} \mathrm{H}_{2}$} & $6.09748-(1644.1 / \mathrm{T})+7.42346 \log (1000 . / \mathrm{T})$ & $80-145$ & Moses et al. (1992) \\
\hline & $7.3147-790.20947 /(\mathrm{T}-10.141)$ & $192-208$ & Lara et al. (1996) \\
\hline \multirow[t]{4}{*}{$\mathrm{C}_{2} \mathrm{H}_{4}$} & $1.5477-1038.1(1 / \mathrm{T}-0.011)+16537 . /(1 / \mathrm{T}-0.011)^{2}$ & $77-89$ & Moses et al. (1992) \\
\hline & $8.724-901.6 /(T-2.555)$ & $89-104$ & Moses et al. (1992) \\
\hline & $50.79-1703 . / \mathrm{T}-17.141 \log (\mathrm{T})$ & $104-120$ & Moses et al. (1992) \\
\hline & $6.74756-585 . /(\mathrm{T}-18.18)$ & $120-155$ & Moses et al. (1992) \\
\hline \multirow[t]{2}{*}{$\mathrm{C}_{2} \mathrm{H}_{6}$} & $10.01-1085 . /(T-0.561)$ & $30-90$ & Lara et al. (1996) \\
\hline & $6.9534-699.10608 /(\mathrm{T}-12.736)$ & $91-305$ & Yaws (2007) \\
\hline $\mathrm{CH}_{3} \mathrm{C}_{2} \mathrm{H}$ & $6.78485-803.72998 /(\mathrm{T}-43.92)$ & $183-267$ & Yaws (2007) \\
\hline $\mathrm{CH}_{2} \mathrm{CCH}_{2}$ & $6.62555-684.69623 /(\mathrm{T}-55.658)$ & $144-294$ & Yaws (2007) \\
\hline $\mathrm{C}_{3} \mathrm{H}_{6}$ & 6.8196-785./(T-26.) & $161-241$ & Yaws (2007) \\
\hline $\mathrm{C}_{3} \mathrm{H}_{8}$ & 7.0189-889.8642/(T-15.916) & $85-176$ & Yaws (2007) \\
\hline \multirow[t]{2}{*}{$\mathrm{C}_{4} \mathrm{H}_{2}$} & $5.3817-3300.5 / \mathrm{T}+16.63415 \log _{10}(1000 . / \mathrm{T})$ & $127-237$ & Lara et al. (1996) \\
\hline & $6.5326-761.68429 /(\mathrm{T}-74.732)$ & $237-478$ & Yaws (2007) \\
\hline $\mathrm{C}_{4} \mathrm{H}_{4}$ & $6.6633-826.0438 /(\mathrm{T}-59.712)$ & $181-454$ & Yaws (2007) \\
\hline $1-\mathrm{C}_{4} \mathrm{H}_{6}$ & $6.98198-988.75(\mathrm{~T}-39.99)$ & $205-300$ & Yaws (2007) \\
\hline $1,2-\mathrm{C}_{4} \mathrm{H}_{6}$ & $6.99383-1041.117 /(\mathrm{T}-30.726)$ & $247-303$ & Yaws (2007) \\
\hline $1,3-\mathrm{C}_{4} \mathrm{H}_{6}$ & $6.84999-930.546 /(\mathrm{T}-34.146)$ & $215-287$ & Yaws (2007) \\
\hline $\mathrm{C}_{4} \mathrm{H}_{8}$ & 6.8429-926.0998/(T-33.) & $192-286$ & Yaws (2007) \\
\hline $\mathrm{C}_{4} \mathrm{H}_{10}$ & 7.0096-1022.47681/(T-24.755) & $135-425$ & Yaws (2007) \\
\hline $\mathrm{C}_{5} \mathrm{H}_{4}$ & 7.986-1509.98716/(T-32.226) & $234-367$ & Yaws (2007) \\
\hline $1-\mathrm{C}_{6} \mathrm{H}_{6}$ & 7.95508-1773.77625/(T-52.937) & $341-449$ & Yaws (2007) \\
\hline $\mathrm{C}_{6} \mathrm{H}_{6}$ & $6.814-1090.43115 /(\mathrm{T}-75.852)$ & $233-562$ & Yaws (2007) \\
\hline $\mathrm{NH}_{3}$ & 7.5874-1013.78149/(T-24.17) & $196-405$ & Yaws (2007) \\
\hline \multirow[t]{2}{*}{$\mathrm{HCN}$} & $11.41-2318 . / \mathrm{T}$ & $132-168$ & Lara et al. (1996) \\
\hline & $8.0258-1608.28491 /(\mathrm{T}-286.893)$ & $260-456$ & Yaws (2007) \\
\hline \multirow[t]{2}{*}{$\mathrm{HNC}$} & $11.41-2318 . / \mathrm{T}$ & $132-168$ & Same as $\mathrm{HCN}$ \\
\hline & $8.0258-1608.28491 /(\mathrm{T}-286.893)$ & $260-456$ & Same as $\mathrm{HCN}$ \\
\hline $\mathrm{C}_{2} \mathrm{~N}_{2}$ & $6.9442-779.237 /(\mathrm{T}-60.078)$ & $146-400$ & Yaws (2007) \\
\hline $\mathrm{C}_{4} \mathrm{~N}_{2}$ & $8.269-2155 . / \mathrm{T}$ & $147-384$ & Yaws (2007) \\
\hline $\mathrm{C}_{6} \mathrm{~N}_{2}$ & $8.269-2155 . / \mathrm{T}$ & $147-384$ & Same as $\mathrm{C}_{4} \mathrm{~N}_{2}$ \\
\hline $\mathrm{HC}_{3} \mathrm{~N}$ & $6.2249-714.01178 /(\mathrm{T}-101.55)$ & $214-315$ & Yaws (2007) \\
\hline $\mathrm{HC}_{5} \mathrm{~N}$ & $6.2249-714.01178 /(\mathrm{T}-101.55)$ & $214-315$ & Same as $\mathrm{HC}_{3} \mathrm{~N}$ \\
\hline $\mathrm{C}_{2} \mathrm{H}_{3} \mathrm{CN}$ & 7.8376-1482.7653/T-25.) & $189-535$ & Yaws (2007) \\
\hline $\mathrm{C}_{2} \mathrm{H}_{5} \mathrm{CN}$ & 7.0414-1270.41907/(T-65.33) & $204-564$ & Yaws (2007) \\
\hline $\mathrm{C}_{3} \mathrm{H}_{5} \mathrm{CN}$ & 7.0406-1617.87915/(T-34.032) & $186-583$ & Yaws (2007) \\
\hline $\mathrm{N}_{2} \mathrm{H}_{2}$ & $7.8288-1698.58081 /(\mathrm{T}-43.21)$ & $270-653$ & Same as $\mathrm{N}_{2} \mathrm{H}_{4}$ \\
\hline $\mathrm{N}_{2} \mathrm{H}_{4}$ & $7.8288-1698.58081 /(\mathrm{T}-43.21)$ & $270-653$ & Yaws (2007) \\
\hline $\mathrm{CH}_{3} \mathrm{NH}_{2}$ & 7.3638-1025.39819/(T-37.938) & $180-430$ & Yaws (2007) \\
\hline $\mathrm{CH}_{3} \mathrm{CN}$ & 6.8376-995.2049/(T-80.494) & $266-518$ & Yaws (2007) \\
\hline $\mathrm{CH}_{3} \mathrm{C}_{2} \mathrm{CN}$ & $6.2249-714.01178 /(\mathrm{T}-101.855)$ & $214-315$ & Yaws (2007) \\
\hline $\mathrm{CH}_{2} \mathrm{NH}$ & 8.0913-1582.91077/(T-33.904) & $175-512$ & From Yaws (2007) value for $\mathrm{CH}_{3} \mathrm{OH}$ \\
\hline
\end{tabular}

Note. In the absence of laboratory data, we assume that the saturated vapor pressure of $\mathrm{HNC}$ is the same as $\mathrm{HCN}$, and that of $\mathrm{N}_{2} \mathrm{H}_{2}$ is the same as $\mathrm{N}_{2} \mathrm{H}_{4}$. We follow Loison et al. (2015) in using the vapor pressure of $\mathrm{CH}_{3} \mathrm{OH}$ for $\mathrm{CH}_{2} \mathrm{NH}$ and in using $\mathrm{H}_{3} \mathrm{CN}$ for $\mathrm{H}_{5} \mathrm{CN}$.

\section{RESULTS}

\subsection{The Effect of Condensation Processes}

We present the results of three models with different assumptions about the condensation and sublimation. Model A is a gas phase only model, with no condensation. Model B includes condensation and sublimation processes as outlined in Section 2.2, and the sedimentation of aerosol particles and their condensates. Model C extends Model B to include the removal of molecules from the gas by haze formation. The model parameters are summarized in Table 3.
The largest effects are seen for the biggest molecules and in particular for those that contain nitrogen. The addition of sedimentation increases the rate of removal of these species from the gas in the lower atmosphere and improves agreement with the observations. However, some molecules are still found to be over-abundant. Further improvement is achieved between 200 and $600 \mathrm{~km}$ for $\mathrm{HCN}, \mathrm{HNC}, \mathrm{HC}_{3} \mathrm{~N}$, and $\mathrm{C}_{2} \mathrm{H}_{5} \mathrm{CN}$ if these molecules are assumed to be incorporated into haze particles.

Below, we discuss the chemistry of several species in more detail. 


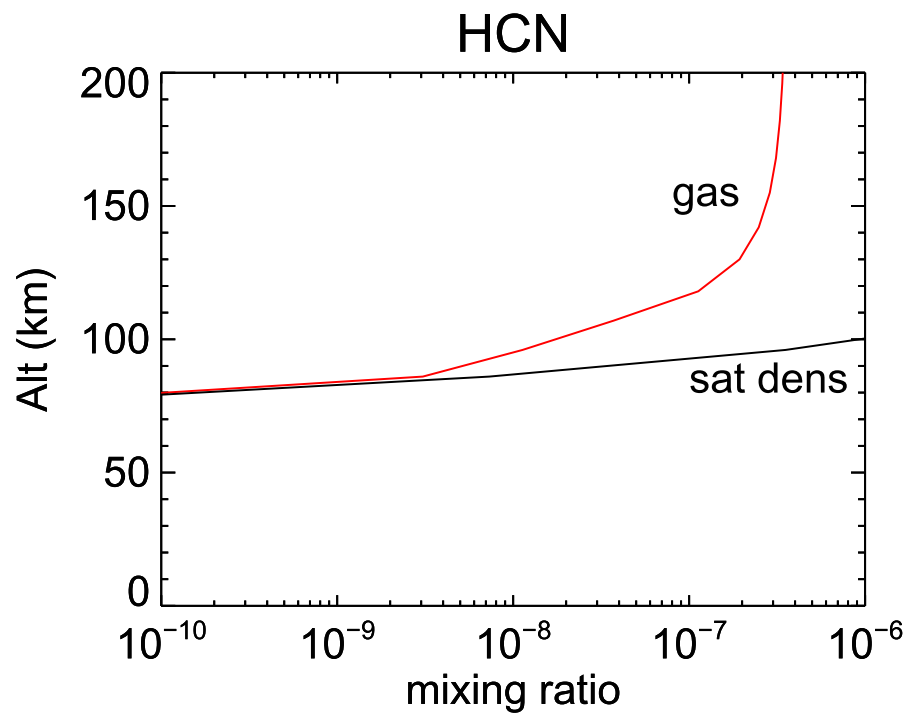

(a)

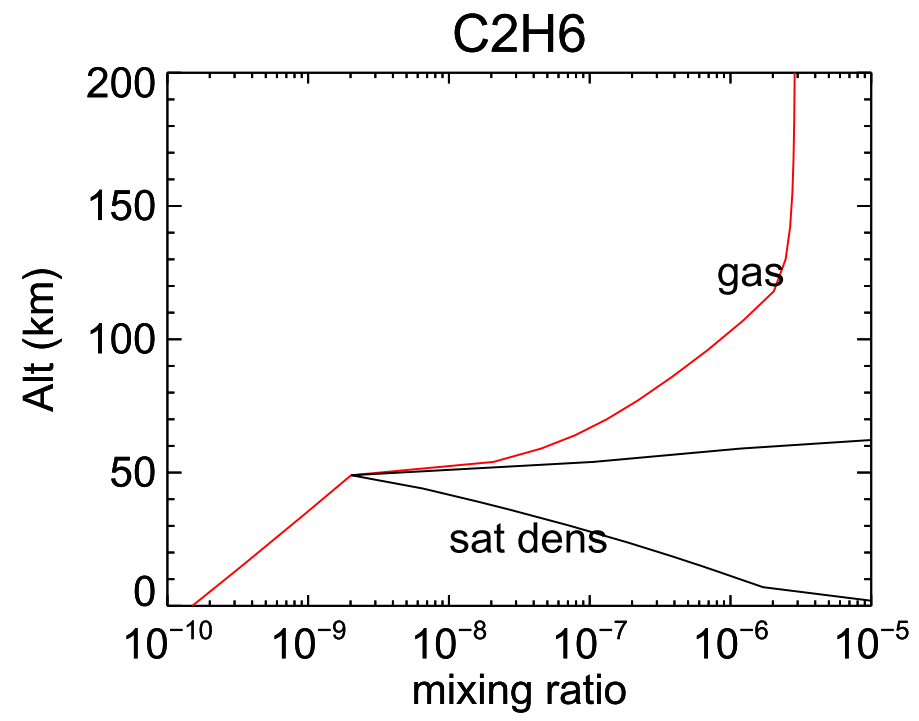

(b)

Figure 2. Comparison of the model results and the calculated mixing ratio under saturation conditions for (a) $\mathrm{HCN}$ and (b) $\mathrm{C}_{2} \mathrm{H}_{2}$. The saturated value (black line) is calculated assuming a pure ice and using the vapor pressure expressions given in Table 2. The model is shown in red. The two lines coincide in the region where the model calculations reach the saturated value and deviate where the calculated mixing ratios are below the saturated values.

Table 3

Summary of Model Assumptions

\begin{tabular}{lccc}
\hline \hline Model & Condensation & Sedimentation & $\begin{array}{c}\text { Haze } \\
\text { Formation }\end{array}$ \\
\hline A & No & No & No \\
B & Yes & Yes & No \\
C & Yes & Yes & Yes \\
\hline
\end{tabular}

Note. Condensation and sublimation rates are discussed in Section 2.2. Sedimentation and haze formation rates are discussed in Section 2.3.

\subsection{Distribution of Nitrogen Molecules}

$$
\text { 3.2.1. } \mathrm{NH}_{3}
$$

In the lower atmosphere, upper limits of the $\mathrm{NH}_{3}$ abundance are provided by Herschel/SPIRE measurements $(65-100 \mathrm{~km}$; Teanby et al. 2013) and from CIRS/Cassini limb observations (110-250 km; Nixon et al. 2013). In the upper atmosphere, the abundance is derived from Cassini/INMS of $\mathrm{NH}_{4}^{+}$(Vuitton et al. 2007) at $1100 \mathrm{~km}$. Cui et al. (2009) claim a detection of $\mathrm{NH}_{3}$ in the ionosphere between 950 and $1200 \mathrm{~km}$. Their value is an order of magnitude larger than that derived by Vuitton et al. and its origin is a matter of debate. It is possible that this high value is due to spent hydrazine fuel (Magee et al. 2009).

Our model abundances in the upper atmosphere are a factor of 10 lower than the observations of Vuitton et al. (2007; Figure 3). Below $250 \mathrm{~km}$, our models are considerably lower (but consistent with) the upper limits derived by Nixon et al. (2010) and Teanby et al. (2013).

The main formation processes for $\mathrm{NH}_{3}$ are

$$
\mathrm{C}_{2} \mathrm{H}_{3}+\mathrm{NH}_{2} \longrightarrow \mathrm{NH}_{3}+\mathrm{C}_{2} \mathrm{H}_{2}<800 \mathrm{~km}
$$

with destruction by photodissociation.

As discussed by Loison et al. (2015) the formation of $\mathrm{NH}_{3}$ via neutral-neutral reactions depends on the presence of $\mathrm{NH}_{2}$, which is not efficiently produced in Titan's atmosphere. The inclusion of ion-molecule chemistry may lead to higher abundances of $\mathrm{NH}_{3}$.

\subsection{2. $\mathrm{HCN}$}

Observations of $\mathrm{HCN}$ have been made from 100 to $1000 \mathrm{~km}$. The millimeter observations of Marten et al. (2002) covered the whole disk and were mainly sensitive to the mid-latitude and equatorial regions. Observations from Cassini/CIRS (Vinatier et al. 2007, 2010), UVIS (Shemansky et al. 2005; Koskinen et al. 2011; Kammer 2015), and INMS (Magee et al. 2009) provide abundance information between 400 and $1000 \mathrm{~km}$. Abundances in the lower atmosphere are also provided by Kim et al. (2005) from Keck observations (Geballe et al. 2003). Vervack et al. (2004) used Voyager 1 Ultraviolet Spectrometer measurements to determine abundances between 500 and $900 \mathrm{~km}$, though the inferred abundances are much higher than other estimates. The differences between the Voyager $1 \mathrm{HCN}$ abundances and those from Cassini may be due to solar cycle variations. Investigating such differences is beyond the scope of this work.

Overall, our models are in good agreement with the observational data (Figure 3). We find that condensation and sublimation are important for $\mathrm{HCN}$ below $500 \mathrm{~km}$. The best fit to the observations is obtained with Model C (Figure 3), where sedimentation and haze formation reduce the abundance of HCN below $500 \mathrm{~km}$.

The main formation processes are

$$
\begin{gathered}
\mathrm{HNC}+\mathrm{H} \longrightarrow \mathrm{HCN}+\mathrm{H} \quad 300-800 \mathrm{~km} \\
\mathrm{CN}+\mathrm{CH}_{4} \longrightarrow \mathrm{HCN}+\mathrm{CH}_{3} \quad 200-600 \mathrm{~km} \\
\mathrm{~N}+\mathrm{CH}_{2} \longrightarrow \mathrm{HCN}+\mathrm{H} \quad 600-900 \mathrm{~km} \\
\mathrm{C}_{2} \mathrm{H}_{3} \mathrm{CN}+h \nu \longrightarrow \mathrm{HCN}+\mathrm{C}_{2} \mathrm{H}_{2} \quad<1000 \mathrm{~km} \\
\mathrm{H}_{2} \mathrm{CN}+\mathrm{H} \longrightarrow \mathrm{HCN}+\mathrm{H}_{2} \quad 900-1300 \mathrm{~km} .
\end{gathered}
$$

Photodissociation plays a role in both the formation of $\mathrm{HCN}$ (via photodisssociation of $\mathrm{C}_{2} \mathrm{H}_{3} \mathrm{CN}$ above $1000 \mathrm{~km}$ ) and in its destruction (forming $\mathrm{CN}$ and $\mathrm{H}$ ). Below $200 \mathrm{~km}$, destruction is by

$$
\mathrm{C}_{2} \mathrm{H}_{3}+\mathrm{HCN} \longrightarrow \mathrm{C}_{2} \mathrm{H}_{3} \mathrm{CN}+\mathrm{H}
$$



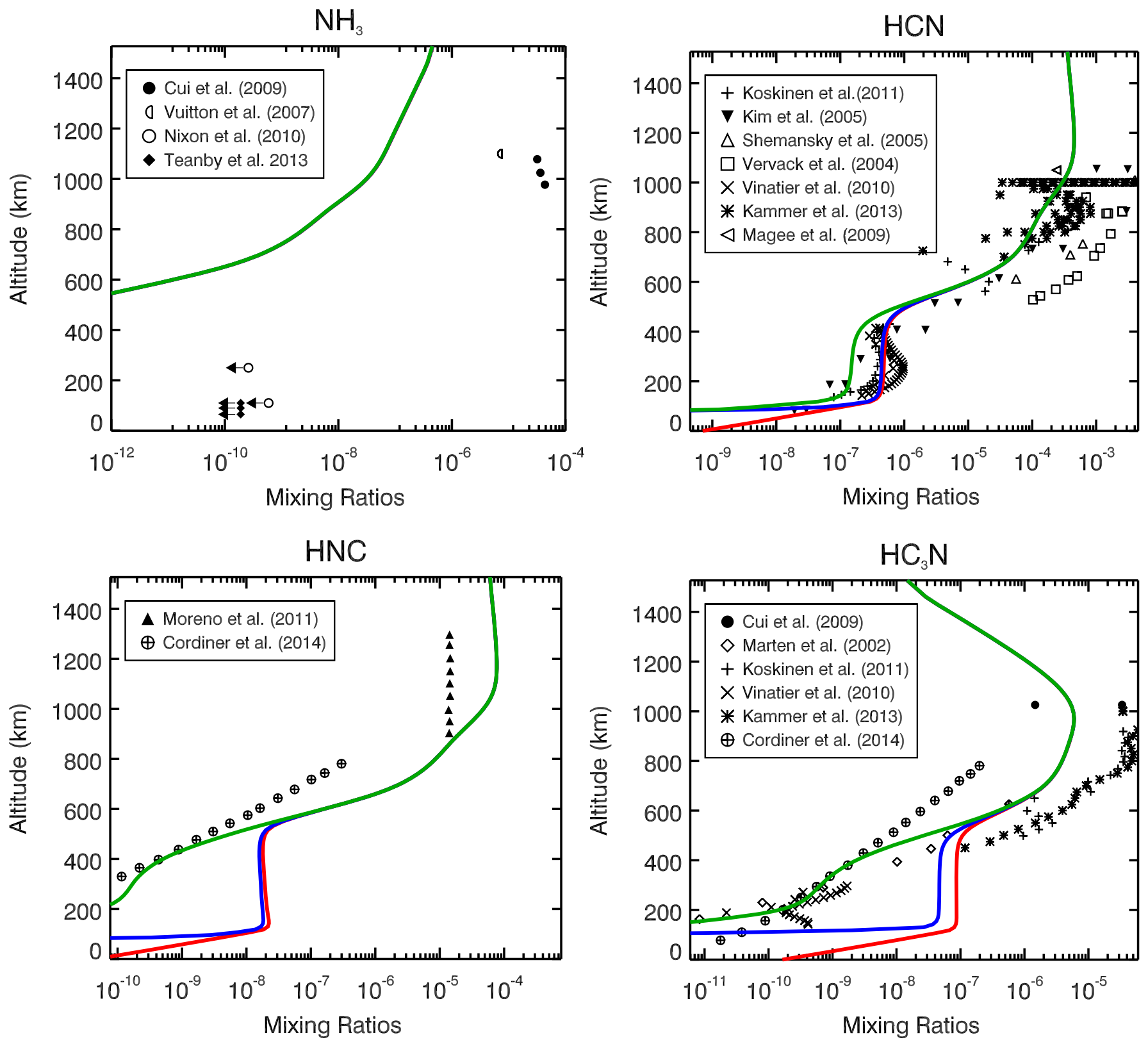

Figure 3. Distribution of some nitrogen-bearing molecules. (Red line = Model A, blue line $=$ Model B, green line $=$ Model C). Cassini/INMS $(\bullet$ Cui et al. 2009; $\triangleleft$ Magee et al. 2009; V Vuitton et al. 2007; Teanby et al. 2013), Cassini/UVIS (+ Koskinen et al. 2011, $\triangle$ Shemansky et al. 2005, * Kammer 2015), Keck ( $\mathbf{\nabla}$ Kim et al. 2005)), Voyager occultation observations ( $\square$ Vervack et al. 2004), Cassini/CIRS (× Vinatier et al. 2010; $\bigcirc$ Nixon et al. 2010), (ム Moreno et al. 2011), IRAM $(\diamond$ Marten et al. 2002), ALMA ( $\oplus$ Cordiner et al. 2014).

\subsection{3. $H N C$}

The first observations of HNC in Titan were made using Herschel/HIFI by Moreno et al. (2011). These measurements do not allow the exact vertical abundance profile to be determined. Several possible profiles can fit the data depending on the mixing ratio and the cut-off altitude assumed. Loison et al. (2015) suggest two possible profiles: one where the mixing ratio of $\mathrm{HNC}$ is $1.4 \times 10^{-5}$ above $900 \mathrm{~km}$ (shown in Figure 3) and another where the mixing ratio is $6 \times 10^{-5}$ above $1000 \mathrm{~km}$. Our models fall between these two ranges.

More recently, Cordiner et al. (2014) used ALMA to detect HNC. They found that the emission mainly originates at altitudes above $400 \mathrm{~km}$ and that there are two emission peaks that are not symmetrical in longitude. We are able to match their best-fit profile reasonably well with model $\mathrm{C}$ (green line; Figure 3), where $\mathrm{HNC}$ forms haze providing the best agreement with the data at lower altitudes.

The main formation channels of $\mathrm{HNC}$ are

$$
\begin{gathered}
\mathrm{C}_{2} \mathrm{H}_{3} \mathrm{CN}+h \nu \longrightarrow \mathrm{HNC}+\mathrm{C}_{2} \mathrm{H}_{2} \quad<900 \mathrm{~km} \\
\mathrm{H}_{2} \mathrm{CN}+\mathrm{H} \longrightarrow \mathrm{HNC}+\mathrm{H}_{2}>900 \mathrm{~km} \\
\mathrm{~N}+\mathrm{CH}_{3} \longrightarrow \mathrm{HNC}+\mathrm{H}>900 \mathrm{~km} .
\end{gathered}
$$

The main destruction process is by reaction with $\mathrm{H}$ atoms forming HCN. This reaction has an activation barrier. In the literature, the value for the activation barrier ranges from 800 to $2000 \mathrm{~K}$ (Talbi et al. 1996; Sumathi \& Nguyen 1998; Petrie 2002; Wakelam et al. 2012). Here we are using the rate from the KIDA database (Wakelam et al. 2012), which has the highest activation barrier of $2000 \mathrm{~K}$. Loison et al. (2015) used 

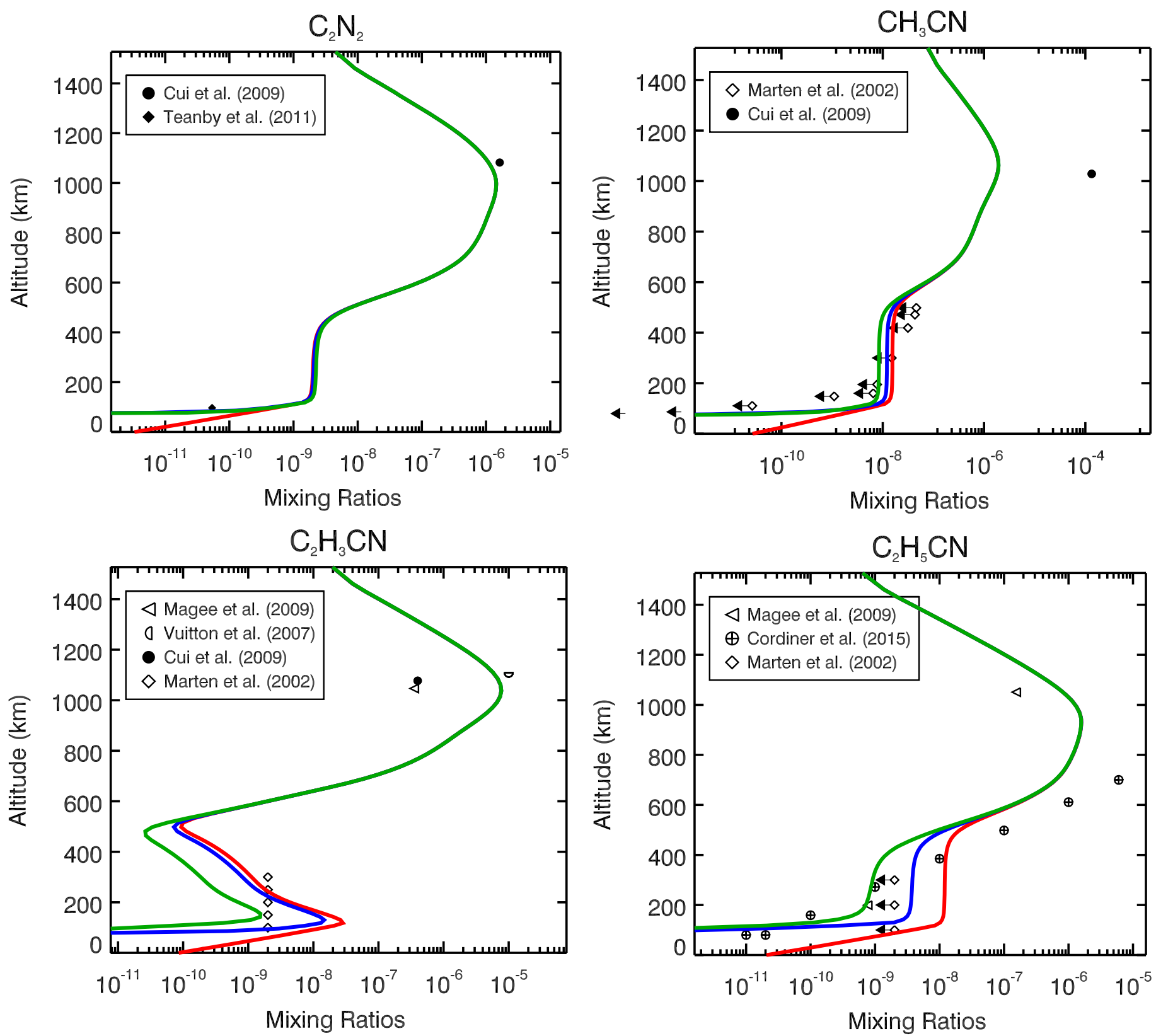

Figure 4. Abundances of more nitrogen-bearing species. Cassini/INMS ( $\bullet$ Cui et al. 2009, $\triangleleft$ Magee et al. 2009, $\neg$ Vuitton et al. 2007), Cassini/CIRS ( $\diamond$ Teanby et al. 2013), IRAM $30 \mathrm{~m}(\diamond$ Marten et al. 2002), ALMA data $(\oplus$ Cordiner et al. 2015).

the lowest value $(800 \mathrm{~K})$, resulting in more efficient $\mathrm{HCN}$ production and consequently a lower gas phase abundance of HNC than we see here. We find that reducing the activation barrier does indeed reduce the mixing ratio of $\mathrm{HNC}$ but does not result in a good fit to the ALMA observations in this region (Figure 5).

\subsection{4. $\mathrm{HC}_{3} \mathrm{~N}$}

$\mathrm{HC}_{3} \mathrm{~N}$ has been observed at altitudes from 200 to $1000 \mathrm{~km}$ (Marten et al. 2002; Vervack et al. 2004; Teanby et al. 2006; Vuitton et al. 2007; Cui et al. 2009; Magee et al. 2009; Vinatier et al. 2010; Cordiner et al. 2014). Below $500 \mathrm{~km}$, our models are in excellent agreement with the observations if it is assumed that $\mathrm{HC}_{3} \mathrm{~N}$ forms aerosols and thus is permanently removed from the gas (Figure 3 bottom left). Condensation and sublimation alone result in an overestimate of the abundance compared to the observations in this region. Good agreement is also seen for all models between 500 and $700 \mathrm{~km}$. Above this, our models tend to under predict the $\mathrm{HC}_{3} \mathrm{~N}$ abundance. Below $100 \mathrm{~km}$, the mixing ratio follows the saturation level, so that below this altitude the mixing ratio is much reduced compared to the gas only model. Better agreement with the observations below $400 \mathrm{~km}$ is obtained in the haze formation model where condensed molecules are assumed to be incorporated into aerosol particles and removed from the gas.

The main formation process below $1000 \mathrm{~km}$ is

$$
\mathrm{C}_{3} \mathrm{~N}+\mathrm{CH}_{4} \longrightarrow \mathrm{HC}_{3} \mathrm{~N}+\mathrm{CH}_{3}
$$


and above $800 \mathrm{~km}$ by

$$
\begin{gathered}
\mathrm{CN}+\mathrm{C}_{2} \mathrm{H}_{2} \longrightarrow \mathrm{HC}_{3} \mathrm{~N}+\mathrm{H} \\
\mathrm{C}_{2} \mathrm{H}_{3} \mathrm{CN}+h \nu \longrightarrow \mathrm{HC}_{3} \mathrm{~N}+\mathrm{H}_{2} .
\end{gathered}
$$

Destruction is by photodissociation

$$
\mathrm{HC}_{3} \mathrm{~N}+h \nu \longrightarrow \mathrm{C}_{3} \mathrm{~N}+\mathrm{H}
$$

and by reaction with $\mathrm{H}$ atoms

$$
\mathrm{H}+\mathrm{HC}_{3} \mathrm{~N}+\mathrm{M} \longrightarrow \mathrm{H}_{2} \mathrm{C}_{3} \mathrm{~N}+\mathrm{M} \text {. }
$$

The observations show a sharp decrease in the abundance of $\mathrm{HC}_{3} \mathrm{~N}$ below $400 \mathrm{~km}$. In our models, this can be accounted for if $\mathrm{HC}_{3} \mathrm{~N}$ is incorporated into haze particles (Model C). An alternative explanation of meridional circulation and condensation in the polar regions has been suggested (Hourdin et al. 2004; Loison et al. 2015).

$$
\text { 3.2.5. } \mathrm{C}_{2} \mathrm{~N}_{2}
$$

Observations of $\mathrm{C}_{2} \mathrm{~N}_{2}$ have been made by Cassini/CIRS (Teanby et al. 2006, 2009) and by Cassini/INMS (Cui et al. 2009; Magee et al. 2009). The models with condensation are in very good agreement with both of these data sets (Figure 4). Without condensation, the abundance in the lower atmosphere is overestimated.

The main formation route for $\mathrm{C}_{2} \mathrm{~N}_{2}$ is by the reaction of $\mathrm{CN}$ and HNC:

$$
\mathrm{CN}+\mathrm{HNC} \longrightarrow \mathrm{C}_{2} \mathrm{~N}_{2}+\mathrm{H}
$$

with destruction via photodissociation forming $\mathrm{CN}$ or by

$$
\mathrm{H}+\mathrm{C}_{2} \mathrm{~N}_{2}+\mathrm{M} \longrightarrow \mathrm{H}_{2} \mathrm{CN}_{2}+\mathrm{M}<400 \mathrm{~km} \text {. }
$$

\subsection{6. $\mathrm{CH}_{3} \mathrm{CN}$}

Submillimeter observations with the IRAM $30 \mathrm{~m}$ telescope detected the $\mathrm{CH}_{3} \mathrm{CN}$ (12-11) rotational line providing a disk average vertical profile up to $500 \mathrm{~km}$, dominated by the equatorial region (Marten et al. 2002). Cassini/CIRS (Nixon et al. 2013) and Cassini/INMS (Vuitton et al. 2007; Cui et al. 2009) provide estimates of the abundance above $1000 \mathrm{~km}$.

All models are in good agreement with the observations below $800 \mathrm{~km}$, though all predict slightly lower abundances than observed between 500 and $600 \mathrm{~km}$. The predicted mixing ratio at $1100 \mathrm{~km}$ is a factor of 10 lower than the observed value of $3 \times 10^{-5}$ Cui et al. (2009).

The main formation processes are

$$
\begin{gathered}
\mathrm{CN}+\mathrm{CH}_{4} \longrightarrow \mathrm{CH}_{3} \mathrm{CN}+\mathrm{H} \quad<900 \mathrm{~km} \\
\mathrm{NH}+\mathrm{C}_{2} \mathrm{H}_{4} \longrightarrow \mathrm{CH}_{3} \mathrm{~N}+\mathrm{H}>900 \mathrm{~km} \\
\mathrm{CH}_{2} \mathrm{NH}+\mathrm{CH} \longrightarrow \mathrm{CH}_{3} \mathrm{CN}+\mathrm{H}<900 \mathrm{~km}
\end{gathered}
$$

with destruction by

$$
\mathrm{CH}_{3} \mathrm{CN}+\mathrm{H} \longrightarrow \mathrm{CN}+\mathrm{CH}_{4}<1200 \mathrm{~km} \text {. }
$$

\subsection{7. $\mathrm{C}_{2} \mathrm{H}_{3} \mathrm{CN}$}

Several observations have placed upper limits on the abundance of $\mathrm{C}_{2} \mathrm{H}_{3} \mathrm{CN}$. Marten et al. (2002) used the IRAM $30 \mathrm{~m}$ telescope to determine the upper limit between 100 and $300 \mathrm{~km}$. Cassini/INMS has provided an upper limit of $4 \times 10^{-7}$ at $1077 \mathrm{~km}$ (Cui et al. 2009), while Cassini/INMS Magee et al. (2009) determined a mixing ratio of $3.5 \times 10^{-7}$ at $1050 \mathrm{~km}$ and Vuitton et al. (2007) found $10^{-5}$ at $1100 \mathrm{~km}$ from observations of ions. M. A. Cordiner et al. (private communication) have detected

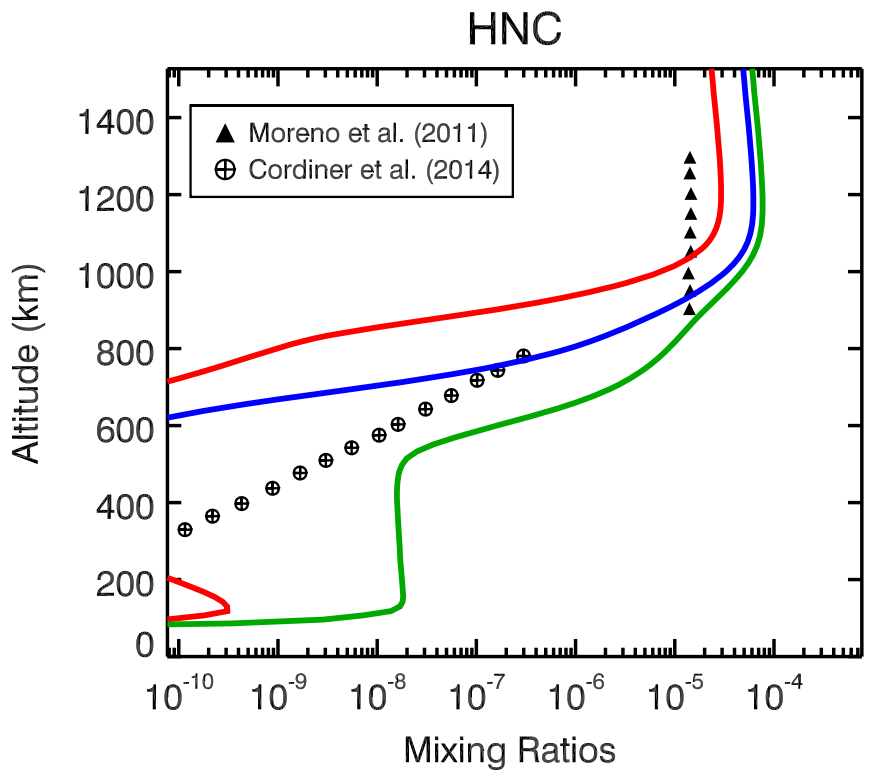

Figure 5. How the HNC abundance depends on the activation barrier of the reaction $\mathrm{H}+\mathrm{HNC} \longrightarrow \mathrm{HCN}+\mathrm{H}$. Green $\mathrm{E}_{A}=2000 \mathrm{~K}$ (Wakelam et al. 2012), blue $\mathrm{E}_{A}=1400 \mathrm{~K}$, and red $\mathrm{E}_{A}=800 \mathrm{~K}$ (Loison et al. 2015). The lower activation barrier results in more $\mathrm{HNC}$ being converted into $\mathrm{HCN}$ but does not result in a better agreement with the altitude distribution seen in the ALMA observations.

$\mathrm{C}_{2} \mathrm{H}_{3} \mathrm{CN}$ in the submillimeter and found an average abundance of $1.9 \times 10^{-9}$ above $300 \mathrm{~km}$. The model abundance of $\mathrm{C}_{2} \mathrm{H}_{3} \mathrm{CN}$ in the upper atmosphere is within a factor of two of the Vuitton et al. (2007) value but 50 times higher than Cui et al. (2009) and Magee et al. (2009).

None of our models have a constant mixing ratio with altitude between 100 and $300 \mathrm{~km}$ as derived from the IRAM observations (Figure 4). Models B and C (which include condensation) are consistent with the derived mixing ratio at a particular altitude, but neither reproduce the constant value between 100 and $300 \mathrm{~km}$. In the upper atmosphere, all models predict mixing ratios within a factor of three of the Magee et al. (2009) result but are over-abundant compared to the other measurement in this region.

The main production mechanism is by the reaction of $\mathrm{CN}$ with $\mathrm{C}_{2} \mathrm{H}_{4}$ :

$$
\begin{gathered}
\mathrm{C}_{2} \mathrm{H}_{3}+\mathrm{HCN} \longrightarrow \mathrm{C}_{2} \mathrm{H}_{5} \mathrm{CN}+\mathrm{H}<200 \mathrm{~km} \\
\mathrm{CN}+\mathrm{C}_{2} \mathrm{H}_{4} \longrightarrow \mathrm{C}_{2} \mathrm{H}_{3} \mathrm{CN}+\mathrm{H} \quad 400-800 \mathrm{~km} \\
\mathrm{H}_{2} \mathrm{C}_{3} \mathrm{~N}+\mathrm{H} \longrightarrow \mathrm{C}_{2} \mathrm{H}_{3} \mathrm{CN}>400 \mathrm{~km} .
\end{gathered}
$$

Gas phase destruction processes are

$$
\mathrm{C}_{2} \mathrm{H}_{3} \mathrm{CN}+h \nu \longrightarrow\left\{\begin{array}{l}
\mathrm{HCN}+\mathrm{C}_{2} \mathrm{H}_{2} \\
\mathrm{HNC}+\mathrm{C}_{2} \mathrm{H}_{2} \\
\mathrm{HC}_{3} \mathrm{~N}+\mathrm{H}_{2}
\end{array}\right.
$$

Below $400 \mathrm{~km}$ haze formation and sedimentation of aerosol particles play an important role in determining the gas mixing ratio in Model C.

\subsection{8. $\mathrm{C}_{2} \mathrm{H}_{5} \mathrm{CN}$}

Upper limits for the abundance of $\mathrm{C}_{2} \mathrm{H}_{5} \mathrm{CN}$ have been determined between 100 and $300 \mathrm{~km}$ from IRAM $30 \mathrm{~m}$ observations (Marten et al. 2002), with abundances in the upper atmosphere provided by Cassini/INMS data (Vuitton 

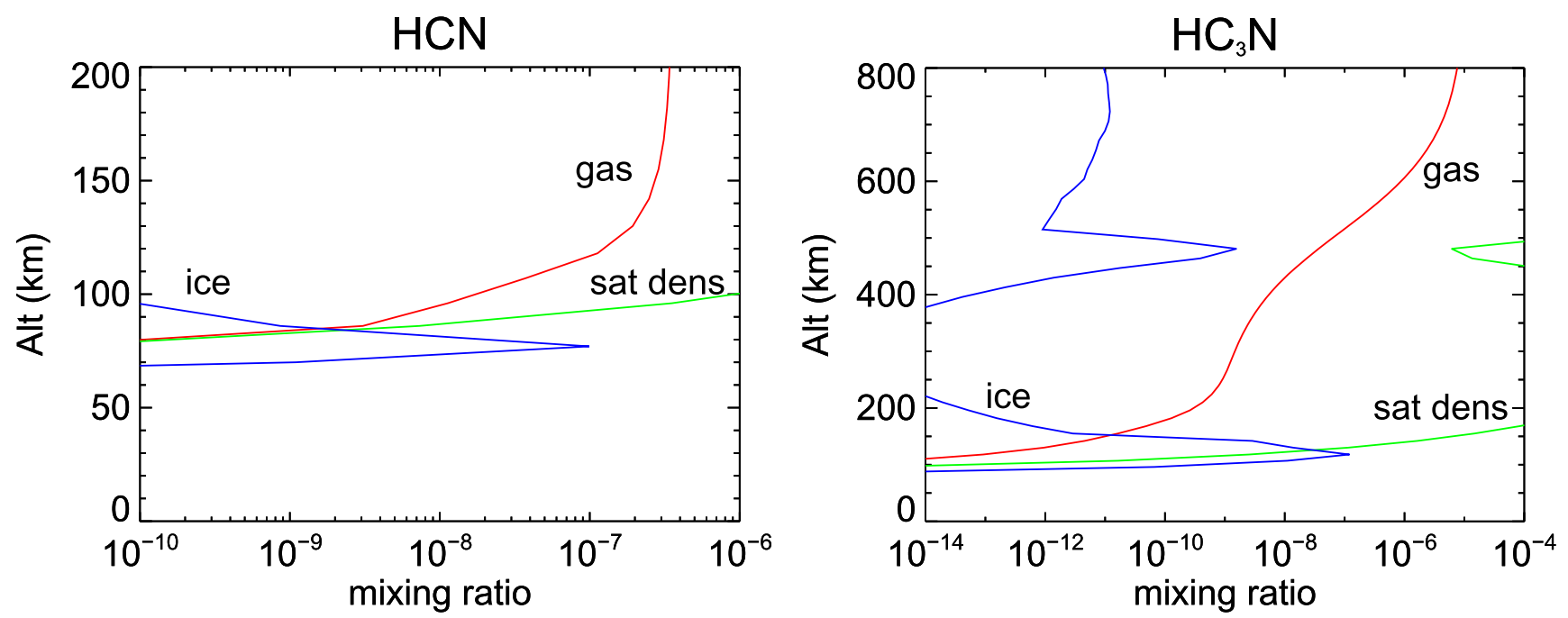

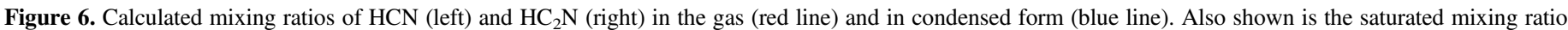

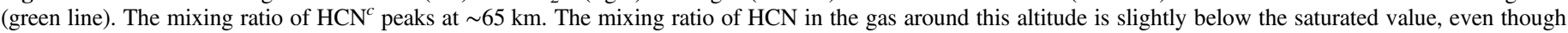

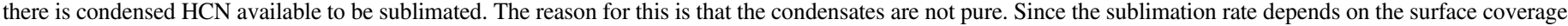

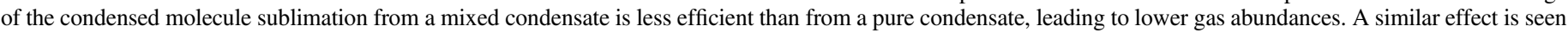

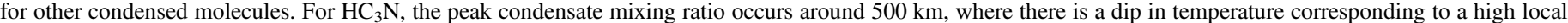
abundance of $\mathrm{HC}_{3} \mathrm{~N}$. Other nitrogen-bearing molecules show similar behavior in this region.

et al. 2007; Cui et al. 2009; Magee et al. 2009). More recently, Cordiner et al. (2015) detected this molecule above $200 \mathrm{~km}$ using ALMA.

Our models overestimate the abundance of $\mathrm{C}_{2} \mathrm{H}_{5} \mathrm{CN}$ in the upper atmosphere (Figure 4), probably because we do not include ion chemistry (for a discussion of this point, see Loison et al. 2015). Below $700 \mathrm{~km}$, Model $\mathrm{C}$ is in excellent agreement with the ALMA data of Cordiner et al.

The main formation process is

$$
\mathrm{CH}_{2} \mathrm{CN}+\mathrm{CH}_{3}+\mathrm{M} \longrightarrow \mathrm{C}_{2} \mathrm{H}_{5} \mathrm{CN}+\mathrm{M} \text {. }
$$

Destruction is by photodissociation

$$
\mathrm{C}_{2} \mathrm{H}_{5} \mathrm{CN}+h \nu \longrightarrow \begin{cases}\mathrm{C}_{2} \mathrm{H}_{4} & +\mathrm{HCN} \\ \mathrm{CH}_{3} & +\mathrm{CH}_{2} \mathrm{CN} \\ \mathrm{C}_{2} \mathrm{H}_{3} \mathrm{CN} & +\mathrm{H}_{2}\end{cases}
$$

or by reaction with $\mathrm{CH}, \mathrm{C}_{2} \mathrm{H}_{3}$, or $\mathrm{C}_{2} \mathrm{H}$.

$$
\begin{gathered}
\mathrm{C}_{2} \mathrm{H}_{5} \mathrm{CN}+\mathrm{CH} \longrightarrow \mathrm{CH}_{2} \mathrm{CN}+\mathrm{C}_{2} \mathrm{H}_{4} \\
\mathrm{C}_{2} \mathrm{H}_{5} \mathrm{CN}+\mathrm{C}_{2} \mathrm{H} \longrightarrow \mathrm{HC}_{3} \mathrm{~N}+\mathrm{C}_{2} \mathrm{H}_{5}<300 \mathrm{~km} \\
\mathrm{C}_{2} \mathrm{H}_{3} \mathrm{CN}+\mathrm{C}_{2} \mathrm{H}_{3} \longrightarrow \mathrm{C}_{2} \mathrm{H}_{3} \mathrm{CN}+\mathrm{C}_{2} \mathrm{H}_{5}<300 \mathrm{~km}
\end{gathered}
$$

\subsection{Condensates in Titan's Atmosphere}

We find several layers at which condensates are abundant with the location being molecule dependent. The first condensate layer is in the lower atmosphere around the tropopause. Here we find condensates of $\mathrm{C}_{2} \mathrm{H}_{2}, \mathrm{C}_{2} \mathrm{H}_{4}, \mathrm{C}_{2} \mathrm{H}_{6}$, and $\mathrm{C}_{3} \mathrm{H}_{8}$ among others. A little further up in the atmosphere, around $65-80 \mathrm{~km}$, several molecules have peaks in condensation e.g., $\mathrm{HCN}, \mathrm{C}_{4} \mathrm{H}_{8}, \mathrm{C}_{4} \mathrm{H}_{2}$, $\mathrm{C}_{2} \mathrm{H}_{3} \mathrm{CN}, \mathrm{C}_{2} \mathrm{~N}_{2}$, and $\mathrm{CH}_{3} \mathrm{C}_{2} \mathrm{H}$. Another layer of $\mathrm{C}_{2} \mathrm{H}_{3} \mathrm{CN}$, $\mathrm{CH}_{3} \mathrm{CN}, \mathrm{C}_{2} \mathrm{H}_{5} \mathrm{CN}$, and $\mathrm{CH}_{3} \mathrm{C}_{2} \mathrm{H}$ forms around $110-130 \mathrm{~km}$. Several molecules also have high condensation levels between 600 and $900 \mathrm{~km}$, e.g., $\mathrm{CH}_{3} \mathrm{C}_{2} \mathrm{H}, \mathrm{HC}_{5} \mathrm{~N}, \mathrm{HC}_{3} \mathrm{~N}, \mathrm{CH}_{3} \mathrm{CN}$, and $\mathrm{C}_{2} \mathrm{H}_{5} \mathrm{CN}$. Figure 6 shows the condensation layers for $\mathrm{HCN}$ and $\mathrm{HC}_{3} \mathrm{~N}$. Both of these molecules have high condensate abundances between 70 and $100 \mathrm{~km}$, but $\mathrm{HC}_{3} \mathrm{~N}$ has a further peak around $500 \mathrm{~km}$ where the atmospheric temperature dips, and the gas phase abundance of this molecule is high.

The net flux of material falling onto the surface of Titan can be calculated from the difference between the atmospheric formation and destruction. Table 4 presents our predictions of the surface flux of nitrogen molecules. These are in solid form and if evenly distributed across Titan's surface would create a layer $4.4 \mathrm{~m}$ deep over a timescale of $1 \mathrm{Gyr}$. This amount of "fixed nitrogen" could be of biological importance.

\section{DISCUSSION AND CONCLUSIONS.}

The removal of molecules by condensation plays an important role in determining the gas phase composition of Titan's atmosphere, as well as creating new aerosols. Condensates are found throughout the atmosphere. For the majority of molecules, condensation is most efficient below the tropopause. Larger molecules, and particularly nitrogen-bearing molecules, have another condensation peak between 200 and $600 \mathrm{~km}$. Relatively high abundances of condensates can also be present above $500 \mathrm{~km}$ if the gas phase abundance of a given molecule is high, e.g., $\mathrm{HC}_{3} \mathrm{~N}, \mathrm{HC}_{5} \mathrm{~N}, \mathrm{CH}_{3} \mathrm{CN}$, and $\mathrm{C}_{2} \mathrm{H}_{5} \mathrm{CN}$. These molecules condense in the region where Titan's haze forms. The effect is enhanced if it is assumed that some molecules can be permanently removed from the gas by being incorporated into aerosol particles. This mechanism was able to bring the abundances of $\mathrm{HC}_{3} \mathrm{~N}, \mathrm{HCN}, \mathrm{HNC}, \mathrm{CH}_{3} \mathrm{CN}$, and $\mathrm{C}_{2} \mathrm{H}_{5} \mathrm{CN}$ into good agreement with the observations below $600 \mathrm{~km}$.

Although Titan possesses a rich organic chemistry it is unclear whether this could lead to life. Photochemically produced compounds on Titan, principally acetylene, ethane, and organic solids, would release energy when consumed with atmospheric hydrogen, which is also a photochemical product. McKay \& Smith (2005) speculate on the possibility of widespread methanogenic life in liquid methane on Titan. On Earth, fixed nitrogen is often a limiting nutrient. Our work shows that an abundant supply of fixed nitrogen, including 
Table 4

Flux of Condensed Molecules onto Titan's Surface

\begin{tabular}{|c|c|c|c|c|}
\hline Molecule & $\begin{array}{c}\text { Flux } \\
\left(\text { molecules } \mathrm{cm}^{-2} \mathrm{~s}^{-1}\right)\end{array}$ & $\begin{array}{c}\text { Flux } \\
\left(\mathrm{g} \mathrm{cm}^{-2} \mathrm{Gyr}^{-1}\right)\end{array}$ & Depth (m) & $\begin{array}{l}\text { Solid/Liquid } \\
\text { at } 95 \mathrm{~K}\end{array}$ \\
\hline$\overline{\mathrm{HCN}^{c}}$ & $-1.2 \times 10^{8}$ & -170 & 2.12 & $\mathrm{~S}$ \\
\hline $\mathrm{HNC}^{c}$ & $-8.1 \times 10^{6}$ & -11.0 & 0.14 & $S$ \\
\hline $\mathrm{HC}_{5} \mathrm{~N}^{c}$ & $-3.410^{6}$ & -13.5 & 0.17 & \\
\hline $\mathrm{C}_{2} \mathrm{~N}_{2}^{\mathrm{c}}$ & $-5.8 \times 10^{5}$ & -15.8 & 0.02 & S \\
\hline $\mathrm{CH}_{3} \mathrm{CN}^{c}$ & $-2.8 \times 10^{5}$ & -0.6 & 0.01 & S \\
\hline $\mathrm{C}_{2} \mathrm{H}_{3} \mathrm{CN}^{c}$ & $-1.5 \times 10^{7}$ & -41.6 & 0.52 & S \\
\hline Total $\mathrm{N}$ & & & $4.4 \mathrm{~m}$ & \\
\hline
\end{tabular}

Note. Also shown are the estimated deposit thicknesses (depths) calculated assuming an average density of $0.8 \mathrm{~g} \mathrm{~cm}^{-3}$.

species of considerable complexity, is available from atmospheric photochemistry.

Creating the kinds of lipid membranes that form the basis of lie on Earth depends on the presence of liquid water. Titan's atmosphere contains little oxygen and the surface temperature is well below that at which liquid water can survive. Instead, surface liquids are hydrocarbons (e.g., Hayes 2016). Therefore, any astrobiological processes, if present, are likely to be quite different to those on Earth. A recent paper by Stevenson et al. (2015) suggests that as an alternative to lipids, membranes could be formed from small nitrogen-bearing organic molecules such as acrylonitrile $\left(\mathrm{C}_{2} \mathrm{H}_{3} \mathrm{CN}\right)$. Stevenson et al. calculate that a membrane composed of acrylonitrile molecules would be thermodynamically stable at cryogenic temperatures and would have a high energy barrier to decomposition.

All of our models predict abundances of $\mathrm{C}_{2} \mathrm{H}_{3} \mathrm{CN}$ that are in agreement with observations above $500 \mathrm{~km}$. Below this, condensation and incorporation into haze are required to bring the predicted mixing ratios down to the values inferred from observations Cordiner et al. (2015). If acrylonitrile were to be involved in life formation it needs to reach the surface of Titan. Our predicted flux of this molecule onto Titan's surface is $1.5 \times 10^{7}$ molecules $\mathrm{cm}^{-2} \mathrm{~s}^{-1}$, or $\sim 41.5 \mathrm{~g} \mathrm{~cm}^{-2} \mathrm{Gyr}^{-1}$, a quantity that is potentially of biological importance.

This research was conducted at the Jet Propulsion Laboratory, California Institute of Technology under contract with the National Aeronautics and Space Administration. Support was provided by the NASA Astrobiology Institute/Titan as a Prebiotic Chemical System. Y.L.Y. was supported in part by the Cassini UVIS program via NASA grant JPL.1459109 to the California Institute of Technology. The authors thank Dr. Run-Lie Shia for his assistance with the KINETICS code and Dr. Panyotis Lavvas for providing the aerosol data used in these models.

Software: KINETICS (Allen et al. 1981).

\section{REFERENCES}

Allen, M., Yung, Y. L., \& Waters, J. W. 1981, JGR, 86, 3617

Anderson, C. M., Samuelson, R. E., Yung, Y. L., \& McLain, J. L. 2016, GeoRL, 43, 3088

Cordiner, M. A., Nixon, C. A., Teanby, N. A., et al. 2014, ApJL, 795, L30
Cordiner, M. A., Palmer, M. Y., Nixon, C. A., et al. 2015, ApJL, 800, L14 Coustenis, A., \& Taylor, F. 1999, Titan: The Earth-like Moon (Singapore: World Scientific)

Cui, J., Yelle, R. V., Vuitton, V., et al. 2009, Icar, 200, 581

De La Haye, V., Waite, J. H., Cravens, T. E., Robertson, I. P., \& Lebonnois, S. 2008, Icar, 197, 110

de La Haye, V., Waite, J. H., Johnson, R. E., et al. 2007, JGRA, 112, A07309

Geballe, T. R., Kim, S. J., Noll, K. S., \& Griffith, C. A. 2003, ApJL, 583, L39

Gladstone, G. R., Stern, S. A., Ennico, K., et al. 2016, Sci, 351, aad8866

Hayes, A. G. 2016, AREPS, 44, 57

Hourdin, F., Lebonnois, S., Luz, D., \& Rannou, P. 2004, JGRE, 109, E12005

Kammer, J. A. 2015, PhD thesis, California Institute of Technology

Kammer, J. A., Shemansky, D. E., Zhang, X., \& Yung, Y. L. 2013, P\&SS, 88,86

Kim, S. J., Geballe, T. R., Noll, K. S., \& Courtin, R. 2005, Icar, 173, 522

Koskinen, T. T., Yelle, R. V., Snowden, D. S., et al. 2011, Icar, 216, 507

Krasnopolsky, V. A. 2009, Icar, 201, 226

Lara, L. M., Lellouch, E., López-Moreno, J. J., \& Rodrigo, R. 1996, JGR, 101, 23261

Lavvas, P. P., Coustenis, A., \& Vardavas, I. M. 2008a, P\&SS, 56, 27

Lavvas, P. P., Coustenis, A., \& Vardavas, I. M. 2008b, P\&SS, 56, 67

Lavvas, P., Yelle, R. V., \& Griffith, C. A. 2010, Icar, 210, 832

Li, C., Zhang, X., Gao, P., \& Yung, Y. 2015, ApJL, 803, L19

Li, C., Zhang, X., Kammer, J. A., et al. 2014, P\&SS, 104, 48

Liang, M.-C., Yung, Y. L., \& Shemansky, D. E. 2007, ApJL, 661, L199

Loison, J. C., Hébrard, E., Dobrijevic, M., et al. 2015, Icar, 247, 218

Lorenz, R., \& Mitton, J. 2008, Titan Unveiled: Saturn's Mysterious Moon Explored (Princeton, NJ: Princeton Univ. Press)

Lunine, J. I. 2005, in Meteorites Comets and Planets: Treatise on Geochemistry, ed. A. M. Davis (Amsterdam: Elsevier), 623

Magee, B. A., Waite, J. H., Mandt, K. E., et al. 2009, P\&SS, 57, 1895

Marten, A., Hidayat, T., Biraud, Y., \& Moreno, R. 2002, Icar, 158, 532

McKay, C. P., \& Smith, H. D. 2005, Icar, 178, 274

Moreno, R., Lellouch, E., Lara, L. M., et al. 2011, A\&A, 536, L12

Moses, J. I., Allen, M., \& Yung, Y. L. 1992, Icar, 99, 318

Niemann, H. B., Atreya, S. K., Bauer, S. J., et al. 2005, Natur, 438, 779

Niemann, H. B., Atreya, S. K., Demick, J. E., et al. 2010, JGRE, 115,12006

Nixon, C. A., Achterberg, R. K., Teanby, N. A., et al. 2010, FaDi, 147, 65

Nixon, C. A., Jennings, D. E., Bézard, B., et al. 2013, ApJL, 776, L14

Petrie, S. 2002, JPCA, 106, 11181

Shemansky, D. E., Stewart, A. I. F., West, R. A., et al. 2005, Sci, 308, 978

Stern, S. A., Bagenal, F., Ennico, K., et al. 2015, Sci, 350, $\operatorname{aad} 1815$

Stevenson, J., Lunine, J., \& Clancy, P. 2015, SciA, 1, 1400067

Strobel, D. F. 1974, Icar, 21, 466

Sumathi, R., \& Nguyen, M. 1998, JPCA, 102, 8013

Talbi, D., Ellinger, Y., \& Herbst, E. 1996, A\&A, 314, 688

Teanby, N. A., Irwin, P. G. J., de Kok, R., et al. 2006, Icar, 181, 243

Teanby, N. A., Irwin, P. G. J., de Kok, R., et al. 2009, Icar, 202, 620

Teanby, N. A., Irwin, P. G. J., Nixon, C. A., et al. 2013, P\&SS, 75, 136

Vervack, R. J., Sandel, B. R., \& Strobel, D. F. 2004, Icar, 170, 91 
Vinatier, S., Bézard, B., Fouchet, T., et al. 2007, Icar, 188, 120

Vinatier, S., Bézard, B., Nixon, C. A., et al. 2010, Icar, 205, 559

Vuitton, V., Yelle, R. V., \& McEwan, M. J. 2007, Icar, 191, 722

Wakelam, V., Herbst, E., Loison, J.-C., et al. 2012, ApJS, 199, 21

Westlake, J. H., Bell, J. M., Waite, J. H., Jr., et al. 2011, JGRA, 116, 3318
Wilson, E. H., \& Atreya, S. K. 2004, JGR, 109, E06002

Yaws, C. L. 2007, Yaws Handbook of Vapor Pressures: Antoine Coefficients (Houston, TX: Gulf Pub.)

Yelle, R. V., Cui, J., \& Müller-Wodarg, I. C. F. 2008, JGRE, 113, E10003

Yung, Y. L., Allen, M., \& Pinto, J. P. 1984, ApJS, 55, 465 